\title{
Procedimientos endoscópicos y pandemia COVID-19 Consideraciones básicas
}

\section{Basic considerations regarding endoscopic procedures during the COVID-19 pandemic}

\author{
William Otero, MD, ${ }^{*}$ Martín Gómez, MD, ${ }^{2}$ Luis A. Ángel, MD, ${ }^{3}$ Oscar Ruiz, MD, ${ }^{3}$ Hernando Marulanda, MD, ${ }^{1}$ Javier Riveros, MD, ${ }^{3}$ \\ Germán Junca, MD, ${ }^{3}$ Hernán Ballén, MD, ${ }^{1}$ Álvaro Rodríguez, MD, ${ }^{3}$ Luis F. Pineda, MD, ${ }^{4}$ Elder Otero, MD, ${ }^{5}$ Lina Otero, MD, ${ }^{6}$ \\ Gilberto Jaramillo, MD, ${ }^{3}$ Johanna Buitrago, MD, ${ }^{3}$ Jairo Rodríguez, MD, ${ }^{3}$ Melissa Bastidas, MD. ${ }^{3}$
}

\footnotetext{
1 Gastroenterología, Universidad Nacional de Colombia, Hospital Universitario Nacional de Colombia y Centro de Gastroenterología y Endoscopia Digestiva. Bogotá, Colombia.

2 Gastroenterología, Universidad Nacional de Colombia y Hospital Universitario Nacional de Colombia, UGEC. Bogotá, Colombia.

3 Universidad Nacional de Colombia y Hospital Universitario Nacional de Colombia. Bogotá, Colombia.

${ }^{4}$ Gastroenterología, Universidad Nacional de Colombia y Gut Médica. Bogotá, Colombia.

${ }_{5}^{5}$ Gastroenterología, Universidad Nacional de Colombia y Centro de Gastroenterología y Endoscopia Digestiva. Bogotá, Colombia.

${ }^{6}$ Centro de Gastroenterología y Endoscopia Digestiva. Bogotá, Colombia.

*Correspondencia: William Otero, waoteror@gmail.com
}

Fecha recibido: $24-03-20$ Fecha aceptado: $26-03-20$

\begin{abstract}
Resumen
EI SARS-Cov-2 es un coronavirus productor de la enfermedad COVID-19. Esta inició en Wuhan, capital de la provincia Hubei, China. En menos de cuatro meses la enfermedad se dispersó por el mundo, lo que dio origen a miles de muertes. La Organización Mundial de la Salud (OMS) la ha declarado pandemia. La humanidad está consternada, múltiples gobiernos han obligado al aislamiento total, con éxito variable debido a la negligencia de parte de la comunidad. En muchas ciudades las instituciones y el personal sanitario no son suficientes para atender la catástrofe. El aislamiento es la única estrategia eficaz para detener el crecimiento logarítmico de COVID-19. El motivo científico del aislamiento es que más del $60 \%$ de los contagios surgen de personas asintomáticas. La enfermedad no solo produce síntomas respiratorios. EI SARS-Cov-2, además, puede producir náuseas, dolor abdominal, vómito, diarrea, anosmia y ageusia. El $50 \%$ de los infectados pueden tener síntomas digestivos, que incluso preceden a los respiratorios. La ruta fecal-oral trasmite el virus, aún sin diarrea. En las unidades de endoscopia están todas las formas de contagio: aerosoles (vómitos, arcadas, eructos, flatos), materia fecal, contacto estrecho, contaminación del ambiente. Se deben suspender todas las endoscopias programadas para diagnóstico. Solo deben realizarse las urgentes y terapéuticas. Todo el personal de endoscopia debe tener medidas de protección estrictas. El paciente debe saber que en la sala de endoscopia puede contagiarse, con constancia en el consentimiento informado. Debe contactarse al paciente posendoscopia vía telefónica a los días 7 y 14 para indagar sobre todos los síntomas mencionados.
\end{abstract}

Palabras clave

Endoscopia, COVID-19, contagio, aerosoles, materia fecal, protección.

\begin{abstract}
SARS-CoV-2 is the coronavirus which produces the dreaded COVID-19. Starting in Wuhan, the capital of China's Hubei province, it has spread it spread throughout the world in less than four months and has caused thousands of deaths. The WHO has declared it to be a pandemic. Humanity is shocked, and many governments have imposed total isolation. It has had varying success due to community negligence. In many cities, institutions and health personnel have not successfully managed this catastrophe. Isolation is the only effective strategy to stop the logarithmic growth of COVID 19. The scientific reason for isolation is that more than $60 \%$ of infections arise from asymptomatic people. SARS-CoV-2 not only produces respiratory symptoms but can also cause nausea, abdominal pain, vomiting, diarrhea, anosmia and ageusia. Fifty percent of those infected may have digestive symptoms which may even precede respiratory symptoms. The fecal-oral route can transmit the virus even when there is no diarrhea. All forms of contagion are found in endoscopy units: aerosols from vomiting, retching, belching, and flatus; fecal matter, close contact, and contamination of the environment. All diagnostic endoscopies should be discontinued. Only urgent and therapeutic endoscopy should be performed. All endoscopy personnel must have strict protection measures. Each patient should be informed, and sign an informed consent form, that the virus can be spread within the endoscopy room. After performance of endoscopy, the patient should be contacted by phone on days 7 and 14 to inquire about all symptoms mentioned.
\end{abstract}

\section{Keywords}

Endoscopy, COVID19, contagion, aerosols, fecal matter, protection. 


\section{INTRODUCCIÓN}

El COVID-19 es una infección potencialmente letal, que tuvo origen en Wuhan, capital de la provincia de Hubei, China (1). Por su rápido esparcimiento y compromiso mundial, la Organización Mundial de la salud (OMS) (2) la ha declarado pandemia (2). El 25 de marzo había 180 países infectados (2). Desde entonces, progresivamente, la humanidad ha asumido estrictamente las recomendaciones emanadas de expertos mundiales, cuyas directrices se mantienen inobjetables durante la evolución de la pandemia. Los procedimientos endoscópicos cobran una importancia inusitada, ya que en las salas de endoscopia están presentes, de manera simultánea, todos los mecanismos de transmisión de esta enfermedad potencialmente letal. Por lo anterior, nuestro grupo considera oportuno realizar una revisión narrativa con base en la información actualizada sobre los aspectos más importantes de la infección por SARS-Cov-2 y los procedimientos endoscópicos.

\section{METODOLOGÍA}

Para este trabajo se hizo una búsqueda en Pubmed con los siguientes términos: ("COVID-19" OR "coronavirus" OR "SARS-Cov-2") AND ("gastrointestinal” OR "transmission" OR "intestinal" OR "digestive" OR "endoscopy" OR "esophagogastroduodenoscopy" OR "colonoscopy"). No hubo restricción de fecha, idioma, ni de ningún otro tipo. Se encontraron 2340 resultados, de los cuales se tomaron los más relevantes para la revisión del tema. También se consultaron de forma manual las referencias de artículos primarios considerados importantes para este trabajo.

A la fecha de esta publicación, el concepto sobre el inicio de la epidemia por SARS-Cov-2, en China, es que el 31 de diciembre de 2019 se habría identificado el paciente cero (0). En ese momento se emitió una alerta epidemiológica en dicho país por varios casos sospechosos de neumonía con evolución desconocida (3). Sin embargo, publicaciones recientes en medios de comunicación de China han informado que el primer paciente en que se confirmó la infección con el nuevo virus fue un hombre de 55 años, el 17 de noviembre de 2019 (4). En este momento se investiga si este paciente sería el "paciente cero", posterior al cual se diseminó con rapidez la infección. Para el 31 de diciembre de 2019 había cerca de 300 pacientes infectados en Wuhan; más adelante, miles de víctimas mortales (2). Esta pandemia se ha propagado muy rápidamente. En Italia, después del primer caso diagnosticado, el 18 de febrero de 2020, el número de infectados ha crecido exponencialmente y actualmente hay cientos de muertes cada día (2).

El SARS-Cov-2 es un virus RNA, de cadena sencilla, con un diámetro de 60-140 nm (1). Pertenece a los coronavi- rus, cuyo nombre deriva de la morfología de su envoltura, en forma de "corona", compuesta por 14 residuos de aminoácidos que interactúan con el receptor 2 de la enzima convertidora de angiotensina (ECA), el cual parece que es su receptor (5-7). En la familia de los coronavirus, hay seis especies que originan enfermedades respiratorias leves en los seres humanos $(8,9)$. Sin embargo, en las últimas dos décadas, dos de ellos han causado enfermedades catastróficas con alta mortalidad, el SARS-Cov en 2002 y el MERS-Cov en 2012 (9). La denominación de estos virus deriva de la patología fundamental que producen, seguida de Cov (coronavirus), SARS-Cov (severe acute respiratory syndrome coronavirus) y el MERS-Cov (Middle East respiratory syndrome coronavirus), que además identifica la localización geográfica de su epidemiología (10). SARS-Cov-2 es el nombre abreviado de la enfermedad que produce el "SARS-CoV-2 related disease" originado en 2019 (10).

Inicialmente fue llamado HCoV19. El SARS-Cov-2 infecta originalmente murciélagos, civetas, tejones, ratas de bambú y camellos salvajes $(1,11)$. El contagio con humanos al parecer pudo haberse originado por el consumo de animales frescos y vivos en el mercado de mariscos de Wuhan (11). $\mathrm{El}$ análisis genómico y filogenético de muestras de lavado bronco-alveolar en nueve pacientes hospitalizados encontraron que el SARS-Cov- 2 comparte una homología del $88 \%$ de la secuencia genética de dos betacoronavirus del murciélago (bat-SL-CoVZC45 y bat-SL-CoVZXC21) (11). Se presume que SARS-Cov-2-19, infectó a la población humana a partir de un reservorio de murciélagos, aunque se ignora qué animal sería el huésped intermedio entre los murciélagos y los humanos. Recientemente se ha postulado que el intermediario pudiera ser un pangolino (12); mamífero placentario parecido físicamente al armadillo, pero distinto en su genética y que pertenece a otra especie (13).

Las manifestaciones clínicas de COVID-19 son variables, van desde una enfermedad leve asintomática, hasta enfermedad severa con falla respiratoria, disfunción multiorgánica, choque séptico y muerte $(1,2,14)$. La fiebre, tos seca y la fatiga son síntomas comunes. La diarrea y otros síntomas digestivos como malestar y dispepsia han sido informados en menos del 5\% de los pacientes (14). Sin embargo, otros autores encontraron que las náuseas, el dolor abdominal y la diarrea pueden presentarse en el 50\% de los pacientes, e incluso preceder a los síntomas respiratorios (15-18). El primer caso identificado en Estados Unidos tuvo síntomas gastrointestinales como náuseas, vómito y diarrea, con documentación del RNA viral en la materia fecal (19). Las náuseas y vómito aparecieron al cuarto día y la diarrea al sexto día de enfermedad (19). En el estudio de China (18), con 73 pacientes hospitalizados por COVID-19, se encontró RNA viral en heces en el 53\% de los pacientes y solo el $65 \%$ tenía diarrea, sugiriendo que el contagio por 
vía fecal, puede ocurrir, aunque no haya diarrea. En el $20 \%$ de los pacientes con COVID-19, el RNA viral permanece positivo en materia fecal, incluso después de ser negativo en el tracto respiratorio (14).

Otras manifestaciones identificadas de forma reciente son la anosmia, disgeusia o ageusia, las cuales pueden estar relacionadas por el tropismo del SARS-Cov-2 con el tejido cerebral que lo convierte en un virus neuroinvasivo (20). Este compromiso del sistema nervioso central también puede participar de la falla respiratoria grave, al comprometer el centro cardiorrespiratorio del tronco cerebral y por vía neurológica, alcanzar mecano y quimiorreceptores en el pulmón y vías respiratorias inferiores (20).

Las características clínicas de más de 44000 casos confirmados en China fueron la siguiente: leve $81 \%$ (sin neumonía o neumonía leve), neumonía severa $14 \%$ (disnea, frecuencia respiratoria $\geq 30$, saturación de $\mathrm{O}_{2} \leq 93 \%$, presión parcial de $\mathrm{O}_{2}$ fracción inspirada de $\mathrm{O}_{2}(\mathrm{PAFI})<300 \mathrm{y} / \mathrm{o}$ infiltrados pulmonares $>50 \%$ ) dentro de $24-48$ horas y crítico $5 \%$ (falla respiratoria, choque séptico, y/o disfunción multiorgánica) (21). Por la rápida evolución de los casos complicados es fundamental la sospecha clínica; además, porque más del $60 \%$ de las transmisiones se hacen a partir de personas asintomáticas (22). El SARS-Cov-2 se trasmite de persona a persona por secreciones respiratorias, materia fecal (oro-fecal) $(14,23,24)$ y superficies contaminadas (1). Además, en un estudio realizado en China en 2005, durante la epidemia del SARS, se encontró RNA viral de SARS-CoV en aguas residuales de hospitales que trataban pacientes con SARS y aunque no correspondía a virus viable, se encontró que podía permanecer hasta 14 días a $4{ }^{\circ} \mathrm{C}$ y 2 días a $20^{\circ} \mathrm{C}(25)$.

La trasmisión más estudiada y la más importante es por microgotas de saliva y aerosoles (26). Una gota es una partícula con un diámetro mayor a $5 \mu \mathrm{m}$ que contiene agua (22). Las gotas pueden entrar en contacto con superficies a una distancia de un metro (26). Con el estornudo, se liberan cerca de 40000 microgotas que salen a una velocidad de $100 \mathrm{~m} / \mathrm{s}$ y con la tos 3000 gotas que salen a una velocidad de $200 \mathrm{~m} / \mathrm{s}$ permaneciendo viable en forma de aerosol hasta por 3 horas $(26,27)$. La carga viral en la saliva es similar a la de la materia fecal y en esta puede persistir hasta 48 horas después de desaparecer de las secreciones respiratorias $(18,24,27)$. Permanece viable en aerosoles durante 3 horas (27). No está claro el número de copias del virus en los aerosoles, como tampoco cuál sería la dosis infectante. En el caso del virus de la influenza se han documentado concentraciones entre 48 a 300 copias del RNA del virus por filtro de muestra positiva, lo que corresponde a una tasa de producción en la exhalación de 3,2 a 20 copias de RNA viral por minuto (28), en cada episodio de tos hay cerca de 16 copias del virus (29).
El SARS-Cov-2 tiene afinidad por los receptores de la enzima convertidora de angiotensina 2 (ECA2), a los cuales se une con su proteína $S(5)$; los cuales, además de estar en las células alveolares tipo II (AT2) (5-7), también se expresan en las células de la mucosa oral, del esófago, del íleon, del colon $(30,31)$ y de la vía biliar $(32)$. La afinidad por estas células del aparato digestivo puede explicar su transmisión por las heces $(17,18)$. Después de entrar a las células del aparato digestivo en su citoplasma se sinterizan las proteínas virales y el RNA viral, se ensamblan nuevos virus, que son liberados al lumen intestinal y llegan a las heces (18). Por la afinidad de SARS-Cov-2 con los receptores de ECA2 ha circulado la hipótesis sobre el posible alto riesgo de las personas que toman inhibidores de ECA2 (IECA2) (33). Sin embargo, esa relación no se ha demostrado y las Asociaciones Americana y Europea de cardiología recomiendan continuar los IECA2 en pacientes con COVID-19 $(34,35)$.

Como se mencionó antes, el impacto epidemiológico de la transmisión es a través de los aerosoles, el contacto estrecho, las superficies inanimadas y la materia fecal. Todas las endoscopias digestivas altas (EDA) y las colonoscopias (CNC) generan aerosoles $(36,37)$. Las EDA producen aerosoles por la tos y las arcadas por las náuseas y las CNC por los flatos, los cuales pueden contaminar los alrededores cercanos (37). La importancia de los aerosoles en el ámbito de los procedimientos médicos ha sido enfatizada por la OMS en una extensa guía sobre el uso racional de equipos de protección personal para SARS-Cov-2, con instrucciones muy precisas y estrictas para los profesionales de la salud que realizan procedimientos que generan aerosoles (38). Además de generar aerosoles, en la sala de endoscopia hay otros fuentes potenciales de contacto tales como: contacto estrecho de persona a persona, contacto con entornos contaminados por salpicaduras de fluidos gastrointestinales (camilla, almohada, sabanas, cobijas, piso, paredes), También cuando se retiran o se insertan accesorios a través del canal de trabajo de los endoscopios, salen líquidos del paciente que pueden incluso contaminar los zapatos de los médicos, como fue demostrado en China (39). Estas observaciones obligan a considerar la sala de endoscopia un "ambiente contaminado" (40).

Por las características especiales de esta infección en el tracto gastrointestinal, las directrices sobre los procedimientos endoscópicos son absolutamente necesarias y deben ser ampliamente difundidas, porque las salas de endoscopias reúnen en un solo sitio los mecanismos más importantes de transmisión del SARS-Cov-2 (aerosoles, materia fecal, superficies contaminadas y contacto estrecho). Por estas circunstancias, pueden convertirse con facilidad en un foco potencial de diseminación de la infección para la institución hospitalaria y para la comunidad, ade- 
más del alto riesgo para el personal médico y de enfermería que participa en los procedimientos endoscópicos.

Para prevenir la transmisión del SARS-Cov-2 dentro de la unidad de endoscopia hay varios aspectos, todos igualmente importantes: i) todos los miembros involucrados en los procedimientos endoscópicos deben cumplir estrictamente los protocolos de protección, ya que todos inevitablemente estarán expuestos a secreciones y líquidos de los pacientes (41); ii) seguir con interés y responsabilidad las recomendaciones publicadas por expertos internacionales en gastroenterología y endoscopia, publicadas y actualizadas permanentemente.

Los expertos de China, Italia y España, que han acumulado extensa y respetable experiencia en la presente pandemia, sugieren que en este momento se opte la siguiente estrategia para evitar la transmisión de la enfermedad, a partir de pacientes asintomáticos hacía el personal hospitalario $\mathrm{u}$ otros pacientes sanos que acuden a procedimientos endoscópicos y muy importante también reducir los gastos en salud para liberar recursos hospitalarios necesarios para combatir la pandemia (42).

1. Suspender todos los procedimientos endoscópicos programados con fines diagnósticos. Asimismo, la consulta externa presencial, la cual debería hacerse de forma virtual (internet o videollamada). Durante el recorrido del paciente de su casa al hospital se puede infectar o infectar a otros y se disminuiría la efectividad del aislamiento.

2. Realizar solamente los procedimientos terapéuticos listados en la Tabla 1, para pacientes con o sin COVID19. La ecoendoscopia biliopancreatica no tiene indicaciones de urgencias. Si hay sospecha de coledocolitiasis y esta es de probabilidad baja o mediana, se puede reemplazar por una colangio-resonancia, que implica menos riesgo biológico. Si hay "alta probabilidad", se debe realizar CPRE.

3. Durante una pandemia, todas las personas deben ser consideradas potencialmente contaminantes (43) y, aunque asintomáticos, se deben estratificar (véase más adelante estratificación de riesgo) con base en el algoritmo de las Figura 1, con el fin de utilizar correctamente las medidas de bioseguridad de acuerdo al riesgo y limitar la exposición a otras personas en sala de espera o de recuperación.

4. El nivel de protección para el personal médico y asistencial sería el 2 si el paciente no está infectado y nivel 3 para los infectados (Tabla 2).

Para el momento actual de la pandemia muchos pacientes ya tienen cita asignada; por ello, consideramos que deben ser contactados con el fin de explicarles sobre el riesgo de asistir a una sala de endoscopia. Además, es posible que
Tabla 1. Indicaciones de endoscopias terapéuticas

\begin{tabular}{|c|c|}
\hline $\begin{array}{l}\text { Escenarios } \\
\text { clínicos }\end{array}$ & Puntos claves a considerar \\
\hline $\begin{array}{l}\text { Hemorragia } \\
\text { digestiva alta } \\
\text { con inestabilidad } \\
\text { hemodinámica }\end{array}$ & $\begin{array}{l}\text { Si no hay inestabilidad, los pacientes pueden } \\
\text { manejarse con inhibidores de bomba de protones } \\
\text { (IBP) intravenosos o por vía oral, según la } \\
\text { evolución y el estado clínico. Si no hay mejoría } \\
\text { o aparece inestabilidad hemodinámica sería } \\
\text { necesaria la endoscopia de urgencias. }\end{array}$ \\
\hline Colangitis & $\begin{array}{l}\text { Es la única patología del tracto biliar que tiene } \\
\text { indicación de CPRE urgente (44). Las demás } \\
\text { indicaciones deben suspenderse, ya que otros } \\
\text { procedimientos, como los drenajes de la vía biliar } \\
\text { por otras indicaciones, pueden realizarse en } \\
\text { radiología, con menor riesgo biológico. }\end{array}$ \\
\hline $\begin{array}{l}\text { Extracción de } \\
\text { cuerpo extraño }\end{array}$ & $\begin{array}{l}\text { Clínicamente hay odinofagia, sialorrea o afagia. } \\
\text { También estaría indicado cuando un estudio de } \\
\text { imagen lo demuestre. }\end{array}$ \\
\hline $\begin{array}{l}\text { Obstrucción del } \\
\text { tracto digestivo }\end{array}$ & Descompresión de vólvulos \\
\hline $\begin{array}{l}\text { Pacientes con } \\
\text { cáncer }\end{array}$ & $\begin{array}{l}\text { Paliación de obstrucción biliar o luminal del tracto } \\
\text { digestivo. } \\
\text { Endoscopias y colonoscopias cuya importancia } \\
\text { diagnóstica sea inaplazable. Biopsias de pacientes } \\
\text { con cáncer. }\end{array}$ \\
\hline
\end{tabular}

Tabla 2. Protección en unidades de endoscopia frente al COVID-19

\begin{tabular}{cll}
\hline Nivel 2 & $\begin{array}{l}\text { Gorro } \\
\text { Tapabocas convencional } \\
\text { Guantes }\end{array}$ & $\begin{array}{l}\text { No existe sospecha de } \\
\text { infección por SARS-CoV-2. } \\
\text { Bata desechable } \\
\text { Protector ocular } \\
\text { Polainas }\end{array}$ \\
\hline Nivel 3 & Gorro & \\
& Mascarilla de alta & Existe sospecha de \\
& infección por SARS-CoV-2. \\
& Guantes dobles & \\
& Bata desechable \\
& protector ocular \\
& Polainas & \\
\hline
\end{tabular}

Tomado y modificado de las "Recomendaciones de la SEED"

algunos de ellos tengan patologías que ameritarían un tratamiento especial y en la entrevista se podrían identificar. En Colombia se ha iniciado de manera oportuna el aislamiento con el fin de evitar el mínimo contacto entre las personas. El fundamento del aislamiento es que la mayoría de los contagios con SARS-Cov- 2 se produce a partir de personas asintomáticas. Otra consideración de nuestro grupo es que 
se suspenda la consulta externa presencial mientras dure el aislamiento. Estas consultas deben seguir haciéndose virtualmente (internet, teléfono, etc.) con la historia clínica abierta y diligenciándola en la forma usual.

\section{ESTRATIFICACIÓN DEL RIESGO DURANTE LA ASIGNACIÓN DE CITAS $(41,45-48)$}

1. Los pacientes para endoscopias deben ser estratificados para el riesgo de COVID-19 un día antes del procedimiento y preferiblemente debe hacerse por teléfono.

2. Debe preguntarse claramente lo siguiente: historia de fiebre, tos, disnea, secreción nasal, diarrea, dolor abdominal, náuseas, anosmia y ageusia. No solo los síntomas respiratorios. Aislar solamente a los sintomáticos respiratorios, es ineficaz para detener el avance de la pandemia.

3. Si existen familiares con los síntomas previos.

4. Si ha tenido contacto con personas sospechosas de COVID-19 o con extranjeros provenientes de cualquier país.

5. Viajes recientes a áreas de alto riesgo (Europa, Latinoamérica, sitios de Colombia donde haya pacientes, hospitales).

6. Durante la entrevista, el día de la endoscopia, debe mantenerse una distancia de por lo menos un metro y, si es posible, utilizar barreras físicas como vidrios.
7. Familiares y directivos de la empresa responsable de los pacientes no puede tener acceso a la sala de endoscopia. Antes de poder entrar debe ser sometido al mismo protocolo de estratificación de riesgo.

8. Los pacientes que son considerados de riesgo para COVID-19 deben estar en áreas separadas antes y después del procedimiento.

9. Todos los pacientes que entren a las salas de endoscopia deben tener equipos de protección (máscaras faciales y guantes).

10. En el consentimiento informado debe incluirse el riesgo de adquirir la infección en la sala de endoscopia.

\section{MEDIDAS PREVENTIVAS DURANTE EL PROCEDIMIENTO $(50,51)$}

1. Garantizar la disponibilidad de todos los elementos de bioseguridad requeridos según el nivel de riesgo (véase Tablas 2 y 3 ), antes de ingresar a la sala de procedimientos.

2. Lavarse las manos con el protocolo estricto, universalmente recomendado.

3. Limitar al máximo la exposición a fómites retirando todos los artículos personales (relojes, anillos, celulares, carnet, distintivos).

4. Si el paciente requiere intubación orotraqueal para el procedimiento, solo el anestesiólogo y su asistente per-

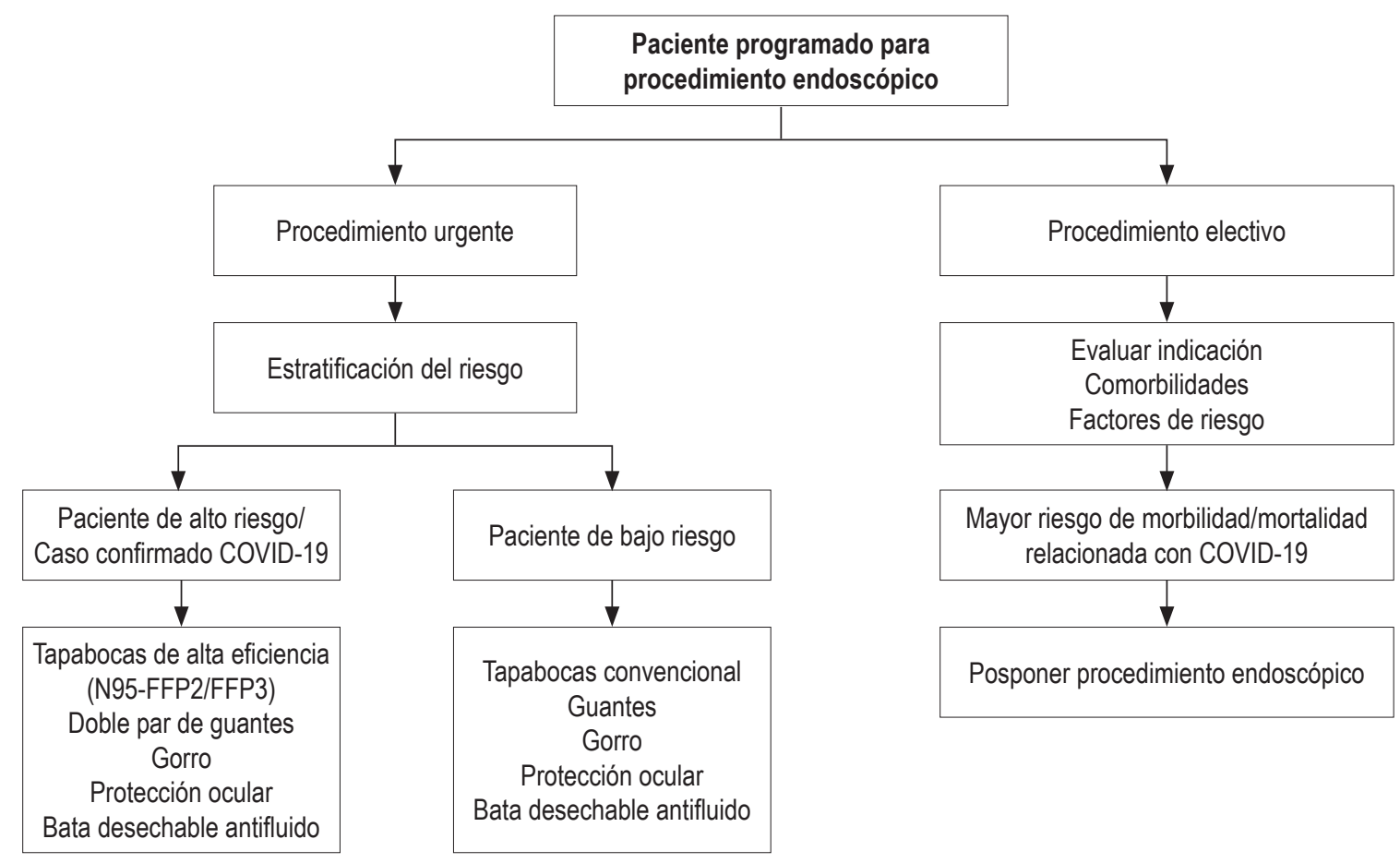

Figura 1. Flujograma de toma de decisiones para procedimientos endoscópicos en pandemia de COVID-19. Adaptado de (49) 
manecen en la sala durante la secuencia de la intubación. El equipo restante se queda afuera.

5. Después de completar el procedimiento, se debe seguir las recomendaciones de los CDC para retirarse el material de bioseguridad (Tabla 3).

6. Solamente el personal absolutamente necesario debe estar en la sala de endoscopia.

\section{RECOMENDACIONES POSPROCEDIMIENTO}

1. Residuos contaminados y accesorios endoscópicos de pacientes con alto riesgo o confirmado COVID-19 deben ser tratados de acuerdo a las recomendaciones sobre desecho de material de alto riesgo.

2. Los pacientes deben contactarse telefónicamente el día 7 y 14 para indagar sobre la aparición de síntomas respiratorios de COVID-19, incluyendo además síntomas gastrointestinales como náuseas, vómito, dolor abdominal o diarrea.

\section{REPROCESAMIENTO DE LOS EQUIPOS POSENDOSCOPIA}

Los episodios de infección asociada a la realización de endoscopia han sido descritos ampliamente e incluyen las bacterias, los hongos, los parásitos y los virus. Sin embargo, el apego a los delineamientos establecidos por las diversas organizaciones internacionales de endoscopia ha permitido que dicho riesgo sea mínimo o ausente para prácticamente todos los casos, para los pacientes y el personal que participa en la ejecución de los mismos en la sala de endoscopia (52). Una excepción, son los duodenoscopios que en su parte distal tienen una "uña" o elevador cuya desinfección es más laboriosa e inclusive imposible en algunos casos (53). Por esta circunstancia, se ha diseñado una parte distal desechable para estos endoscopios (53).

La seguridad de los procedimientos de endoscopia está garantizada, si se cumplen los lineamientos establecidos de desinfección de alto nivel de los equipos de endoscopia y sus accesorios (pinzas y papilótomos) (54), se cumplen los procedimientos de limpieza y desinfección de las unidades de endoscopia durante y al final de la sesión, protegiendo así directamente a los pacientes (55-57) y se siguen los protocolos que garantizan la seguridad del personal que los realiza y sus auxiliares (55).

En la actualidad, con la pandemia de COVID-19, las instrucciones sobre el procedimiento de lavado y desinfección de equipos no se han modificado, ya que las existentes son suficientes para la eliminación del virus $(58,59)$. En cambio, sí existen nuevas recomendaciones para los pacientes $y$ el personal de salud implicado en el procedimiento, para evitar la amplificación del contagio a ambos grupos. Las recomendaciones principales incluyen, como mencionamos antes, no realizar procedimientos diagnósticos, solamente los exámenes urgentes y que sean con fines terapéuticos, con los niveles de protección previamente mencionados. Para la limpieza de áreas, superficies, elementos y manos deben considerarse las características de los antisépticos y susceptibilidad del virus. En primera instancia debe garantizarse el retiro del material orgánico de las mismas mediante el uso de jabones y detergentes y frote con el material de limpieza. En la Tabla 4 se muestran los antisépticos, con sus respectivas concentraciones para garantizar la reducción del virus en al menos 3-4 logaritmos (Tabla 1) (58).

Tabla 3. Elementos de bioseguridad recomendados para el personal de salud (63)

\begin{tabular}{|c|c|c|c|}
\hline Área & Personal & Actividad & Elementos de bioseguridad \\
\hline $\begin{array}{l}\text { Hospitalización } \\
\text { Urgencias } \\
\text { Consulta externa }\end{array}$ & \multirow[t]{3}{*}{$\begin{array}{l}\text { Trabajador } \\
\text { de la salud* }\end{array}$} & $\begin{array}{l}\text { Contacto directo con el paciente en } \\
\text { procedimientos que no generan aerosoles }\end{array}$ & $\begin{array}{l}\text { Mascarilla quirúrgica, visor, careta o monogafas. Bata manga larga } \\
\text { anti fluido. Guantes no estériles. Vestido quirúrgico debajo de la } \\
\text { bata que se retira al final del turno. Opcional: gorro }\end{array}$ \\
\hline $\begin{array}{l}\text { Unidad de Cuidados } \\
\text { Intensivos } \\
\text { Salas de cirugía }\end{array}$ & & $\begin{array}{l}\text { Contacto directo con el paciente con } \\
\text { sospecha o confirmación de COVID-19, } \\
\text { en procedimientos que generan aerosoles. }\end{array}$ & $\begin{array}{l}\text { Respirador N95. Visor, careta o monogafas. Bata manga larga } \\
\text { antifluido. Guantes no estériles. Vestido quirúrgico debajo de la } \\
\text { bata que se retira al final del turno. Opcional: gorro }\end{array}$ \\
\hline & & Procedimiento quirúrgico & $\begin{array}{l}\text { Respirador N95. Visor, careta o monogafas. Bata manga larga } \\
\text { antifluido. Guantes estériles. Vestido quirúrgico debajo de la bata } \\
\text { que se retira al final del turno. Gorro, polainas. }\end{array}$ \\
\hline
\end{tabular}

*Trabajador de la salud: persona que con motivo de su actividad atienda o deba estar en contacto con el paciente 
Tabla 4. Concentraciones de antisépticos que reducen la concentración de Coronavirus $\geq 3$ logaritmos*

\begin{tabular}{lc}
\hline \multicolumn{1}{c}{ Productos evaluados } & Tiempo de exposición \\
\hline 2-Propanol $100 \%$ & 30 segundos \\
2-Propanol $70 \%$ & 30 segundos \\
Etanol $78 \%$ & 30 segundos \\
2-Propanol $45 \%, 1$-propanol $30 \%$ & 30 segundos \\
Vinagre de vino & 60 segundos \\
Formaldeído 0,7\% & 2 minutos \\
Formaldeído 1\% & 2 minutos \\
Glutardialdeído 0,5\% & 2 minutos \\
Glucoprotamin 26\% & 2 minutos \\
\hline
\end{tabular}

* Actividad virucida en SARS-CoV (58)

\section{RESIDENTES DE GASTROENTEROLOGÍA}

1. Los alumnos son parte integral en la mayoría de las unidades endoscopia de los hospitales universitarios. En la actual pandemia por COVID-19, su papel con respecto a los procedimientos debe ser reevaluados. $\mathrm{Su}$ participación aumenta el tiempo de duración del procedimiento y con ello el riesgo de exposición (60). Por lo tanto, no deben realizar procedimientos endoscópicos ni estar en las salas de endoscopia.

2. Su actividad debería llevarse a cabo en áreas limpias y con actividades de menor riesgo: diligenciamiento de los consentimientos y los informes. Continuar sus actividades académicas mediante videoconferencias, $y$ simuladores (si existieran), adecuar en las salas limpias, motores para que miren y aprendan teóricamente la ejecución de los procedimientos (terapéuticos).

3. Como los residentes de gastroenterología, generalmente tienen una primera especialidad, podrían brindar apoyo sumándose a la fuerza laboral de gestión de COVID-19 (61). Si no tienen una primera especialidad, igualmente podrían apoyar en la atención de pacientes con COVID-19.

4. Los que realicen prácticas en diferentes centros hospitalarios deben ser reasignados y mantenerse en una sola institución, ya que los desplazamientos pueden favorecer una propagación accidental entre distintos centros de atención (62).

\section{RECOMENDACIONES GENERALES ADICIONALES (63)}

Estas recomendaciones y las respectivas dotaciones deben estar a cargo del departamento de calidad y de vigilancia epidemiológica y del de infectología.

1. Los pacientes sospechosos o confirmados deben usar tapabocas y aislarse o separarse de otros pacientes por una distancia de al menos un metro. Idealmente contar con un área de recuperación exclusiva para pacientes sospechosos.

2. Procurar que los procedimientos se realicen en una sala de aislamiento de infecciones transmitidas por el aire que cumpla con los requisitos de bioseguridad de nivel 3.

3. Garantizar elementos de bioseguridad para todos los profesionales que se encuentran dentro de la unidad de endoscopia.

4. Insistir y capacitar a todo el personal con el método correcto de higiene de manos. El lavado de las manos, tiene un protocolo, que debe ser de obligatorio conocimiento y cumplimiento por todos.

5. El retiro y desecho de los elementos de bioseguridad se debe realizar en una antesala limpia, por fuera de la sala de procedimientos y separada del resto de las instalaciones de la unidad de endoscopia.

6. Se debe tomar precauciones adicionales para evitar la contaminación de elementos y equipos en la estación de trabajo (computador, escritorio, lapiceros).

7. Los baños son sitios potenciales de transmisión. Deben estar completamente separados de los sitios que utilizan los pacientes y el personal de salud.

8. Incrementar la frecuencia en su lavado y desinfección.

9. Restringir el número de personas dentro de la sala de procedimientos (máximo 5) con el fin de disminuir el riesgo de transmisión y el uso de material crítico de bioseguridad.

El SARS.Cov-2 19 es muy estable sobre superficies. Se ha encontrado que permanece viable en aerosoles durante 3 horas, en plástico y acero inoxidable hasta 72 horas mientras que sobre el cobre no se encuentra virus viable a las 4 horas. En cartón no se encontró virus viable a las 24 horas. Comparte estabilidad similar con el SARS-CoV-1 en la mayoría de las sustancias (27).

La persistencia del SARS-Cov-2 y los agentes químicos que lo neutralizan, se muestran en las Tablas 5 y 6 respectivamente (62).

Los servicios de endoscopia deben mantener su independencia frente a potenciales presiones de autoridades administrativas jerárquicamente superiores, ya que estas recomendaciones están basadas en la más reciente literatura científica publicada, sobre las características clínicas, modos de transmisión y, así mismo, guías universales sobre el manejo actual de la pandemia de COVID-19, impartidas por la OMS y por expertos de la Asociación Americana de Endoscopia Gastrointestinal (ASGE), Asociación China de Gastroenterología, Asociación Española de Enfermedades Digestivas y la experiencia de gastroenterólogos y endoscopistas. 
Tabla 5. Persistencia de SARS-Cov-2 en diferentes superficies (62)

\begin{tabular}{lccc}
\hline Superficie & Inoculo & $\begin{array}{c}\text { Temperatura } \\
{ }^{\circ} \mathrm{C}\end{array}$ & $\begin{array}{c}\text { Tiempo de } \\
\text { persistencia }\end{array}$ \\
\hline Acero & $10^{5}$ & 20 & 48 horas \\
Aluminio & $5 \times 10^{3}$ & 21 & $2-8$ horas \\
Metal & $10^{7}$ & Ambiente & 5 días \\
Madera & $10^{5}$ & Ambiente & 4 días \\
Papel & $10^{5}$ & Ambiente & $4-5$ días \\
Vidrio & $10^{5}$ & Ambiente & $\leq 5$ días \\
Plástico & $10^{5}$ & $22-25$ & 5 días \\
PVC & $10^{5}$ & 21 & $<5$ días \\
Silicona & $10^{3}$ & 21 & 5 días \\
Látex & $10^{3}$ & 21 & $<8$ horas \\
Cerámica & $5 \times 10^{3}$ & 21 & 5 días \\
Teflón & $10^{3}$ & 21 & 5 días \\
\hline
\end{tabular}

Tabla 6. Agentes químicos que reducen la infectividad del virus (62)

\begin{tabular}{lccc}
\hline \multicolumn{1}{c}{ Agente } & Concentración & $\begin{array}{c}\text { Tiempo de } \\
\text { exposición }\end{array}$ & $\begin{array}{c}\text { Reducción } \\
\text { infectividad } \\
\text { Log }_{10}\end{array}$ \\
\hline Etanol & $80-95 \%$ & 30 segundos & $4-5,5$ \\
2-Propanol & $70-100 \%$ & 30 segundos & $3,3-4$ \\
Clorexidina & $0,02 \%$ & 10 minutos & $0,7-0,8$ \\
Hipoclorito de sodio & $0,21 \%$ & 30 segundos & $>4$ \\
Peróxido de & $0,5 \%$ & 1 minutos & $>4$ \\
hidrógeno & $1 \%$ & 2 minutos & $>3$ \\
Formaldehido & $0,5-2,5 \%$ & $2-5$ minutos & $>4$ \\
Glutaraldehido & $1 \%$ & 1 minutos & $>4$ \\
Yodo povidona & & & \\
\hline
\end{tabular}

\section{Conflicto de intereses}

Ninguno.

\section{Agradecimientos}

A los profesores Diego Aponte y Fernando García del Risco, por la revisión del manuscrito y sus recomendaciones.

\section{REFERENCIAS}

1. Zhou W. The coronavirus prevention handbook: 101 science-based tips that could save your life [Internet]. 2020 [acceso 2020 Mar 26]. Disponible en: https://www. overdrive.com/search?q=76E6C249-9E76-47F7-B887592DCDB1B16E

2. WHO Director-General's opening remarks at the media briefing on COVID-19 - 11 March 2020 [Internet]. [acceso 2020 Mar 25]. Disponible en: https://www.who.int/dg/ speeches/detail/who-director-general-s-opening-remarksat-the-media-briefing-on-covid-19---11-march-2020

3. Huang C, Wang Y, Li X, Ren L, Zhao J, Hu Y, et al. Clinical features of patients infected with 2019 novel coronavirus in Wuhan, China. The Lancet. 2020;395(10223):497-506. https://doi.org/10.1016/S0140-6736(20)30183-5

4. China's first confirmed Covid-19 case traced back to November 17 [Internet]. South China Morning Post. 2020 [acceso 2020 Mar 24]. Disponible en: https://www.scmp. com/news/china/society/article/3074991/coronaviruschinas-first-confirmed-covid-19-case-traced-back

5. Hoffmann M, Kleine-Weber H, Krüger N, Müller M, Drosten C, Pöhlmann S. The novel coronavirus 2019 (2019-nCoV) uses the SARS-coronavirus receptor ACE2 and the cellular protease TMPRSS2 for entry into target cells [Internet]. Molecular Biology; 2020 Jan [acceso 2020 Mar 23]. Disponible en: http://biorxiv.org/lookup/doi/10.1101/2020.01.31.929042 https://doi.org/10.1101/2020.01.31.929042. [Epub ahead of print].

6. Zou X, Chen K, Zou J, Han P, Hao J, Han Z. Single-cell RNA-seq data analysis on the receptor ACE2 expression reveals the potential risk of different human organs vulnerable to 2019-nCoV infection. Front Med [Internet]. 2020 Mar 12 [acceso 2020 Mar 23]; Disponible en: http://link.springer.com/10.1007/s 1 1684-020-0754-0 https://doi.org/10.1007/s11684-020-0754-0

7. Zhao Y, Zhao Z, Wang Y, Zhou Y, Ma Y, Zuo W. Single-cell RNA expression profiling of ACE2, the putative receptor of Wuhan 2019-nCov [Internet]. Bioinformatics; 2020 Jan [acceso 2020 Mar 23]. Disponible en: http:// biorxiv.org/lookup/doi/10.1101/2020.01.26.919985 https://doi.org/10.1101/2020.01.26.919985

8. Smith JA, Judd J. COVID-19: Vulnerability and the power of privilege in a pandemic. Health Promot J Austr [Internet]. 2020 Mar 20 [acceso 2020 Mar 20]; Disponible en: http://doi.wiley.com/10.1002/hpja.333 https://doi.org/10.1002/hpja.333. [Epub ahead of print].

9. WHO. Summary of probable SARS cases with onset of illness from 1 November 2002 to 31 July 2003. [Internet]. Dec 31, 2003 [acceso 2020 Mar 19]. https://www. who. $\mathrm{int} / \mathrm{csr} / \mathrm{sars} /$ country/table2004 04 21/en/

10. Li J-Y, You Z, Wang Q, Zhou Z-J, Qiu Y, Luo R, et al. The epidemic of 2019-novel-coronavirus (2019-nCoV) pneumonia and insights for emerging infectious diseases in the future. Microbes Infect. 2020;22(2):80-5. https://doi.org/10.1016/j.micinf.2020.02.002

11. Lu R, Zhao X, Li J, Niu P, Yang B, Wu H, et al. Genomic characterisation and epidemiology of 2019 novel coronavirus: implications for virus origins and receptor binding. The Lancet. 2020;395(10224):565-74. https://doi.org/10.1016/S0140-6736(20)30251-8

12. Zhang T, Wu Q, Zhang Z. Probable Pangolin Origin of SARS-CoV-2 Associated with the COVID-19 Outbreak. Curr Biol. 2020 Mar;S0960982220303602. https://doi.org/10.1016/j.cub.2020.03.022. [Epub ahead of print]. 
13. Pangolin. In: Wikipedia [Internet]. 2020 [acceso 2020 Mar 23]. Disponible en: https://en.wikipedia.org/w/index.php ?title $=$ Pangolin \&oldid $=947412030$

14. Gu J, Han B, Wang J. COVID-19: Gastrointestinal manifestations and potential fecal-oral transmission. Gastroenterology. 2020;S001650852030281X. https://doi.org/10.1053/j.gastro.2020.02.054

15. WEO ALERT: Wuhan proposal for Safety in Digestive Endoscopy [Internet]. [acceso 2020 Mar 23]. Disponible en: http://www.worldendo.org/2020/02/05/weo-alertwuhan-proposal-for-safety-in-digestive-endoscopy/

16. Pan L, Mu M, Yang P, Sun Y, Yan J, Li P, et al. Clinical characteristics of COVID-19 patients with digestive symptoms in Hubei, China: a descriptive, cross-sectional, multicenter study. Article in press.

17. Luo S, Zhang X, Xu H. Don't overlook digestive symptoms in patients with 2019 novel coronavirus disease (COVID-19).Clin GastroenterolHepatol.2020Mar20.pii:S1542-3565(20)304018. doi: 10.1016/j.cgh.2020.03.043. [Epub ahead of print]

18. Xiao F, Tang M, Zheng X, Liu Y, Li X, Shan $H$. Evidence for gastrointestinal infection of SARSCoV-2. Gastroenterology. 2020;S0016508520302821. doi: 10.1053/j.gastro.2020.02.055 [Epub ahead of print]

19. Holshue ML, DeBolt C, Lindquist S, Lofy KH, Wiesman J, Bruce H, et al. First Case of 2019 Novel Coronavirus in the United States. N Engl J Med. 2020;382(10):929-36. https://doi.org/10.1056/NEJMoa2001191

20. LiY,BaiW,HashikawaT.TheneuroinvasivepotentialofSARS$\mathrm{CoV} 2$ may be at least partially responsible for the respiratory failure of COVID-19 patients. J Med Virol. 2020;jmv.25728. https://doi.org/10.1002/jmv.25728

21. WuZ,McGoogan JM. Characteristics of and Important Lessons From the Coronavirus Disease 2019 (COVID-19) Outbreak in China: Summary of a Report of 72314 Cases From the Chinese Center for Disease Control and Prevention. JAMA [Internet]. 2020 Feb 24 [acceso 2020 Mar 26]; Disponible en: https:// jamanetwork.com/journals/jama/fullarticle/2762130 https://doi.org/10.1001/jama.2020.2648

22. Center for Disease Control and Prevention. Filtering out Confusion: Frequently Asked Questions about Respiratory Problems [Internet]. [cited 2020 Mar 23]. Available from: https://www.cdc.gov/niosh/docs/2018-128/pdfs/2018128.pdf ?id=10.26616/NIOSHPUB2018128

23. Yeo C, Kaushal S, Yeo D. Enteric involvement of coronaviruses: is faecal-oral transmission of SARS-CoV-2 possible? Lancet. 2020;5(4):335-337. https://doi.org/10.1016/ S2468-1253(20)30048-0

24. CUHK Finds that the Coronavirus Can Persist in Stool after Its Clearance in Respiratory Tract Will Conduct Stool Test for People in Quarantine Camps for Early Identification [Internet]. [acceso 2020 Mar 21]. Disponible en: https:// www.med.cuhk.edu.hk/press-releases/cuhk-finds-thatthe-coronavirus-can-persist-in-stool-after-its-clearance-inrespiratory-tract-will-conduct-stool-test-for-people-in-quarantine-camps-for-early-identification
25. WangXW,LiJ,Guo T,ZhenB,KongQ,YiB, etal.Concentration and detection of SARS coronavirus in sewage from Xiao Tang Shan hospital and the $309^{\text {th }}$ Hospital of the Chinese People's Liberation Army. Water Sci Technol. 2005;52(8):213-21. https://doi.org/10.2166/wst.2005.0266

26. Wei J, Li Y. Airborne spread of infectious agents in the indoor environment. Am J Infect Control. 2016;44(9):S102-8. https://doi.org/10.1016/j.ajic.2016.06.003

27. Doremalen N, Bushmaker T, Morris DH, et al. Aerosol and Surface Stability of SARS-CoV-2 as Compared with SARSCoV-1 [published online ahead of print, 2020 Mar 17]. N Engl J Med. 2020;10.1056/NEJMc2004973. doi:10.1056/ NEJMc2004973.

28. Fabian P, McDevitt JJ, DeHaan WH, Fung ROP, Cowling BJ, Chan $\mathrm{KH}$, et al. Influenza Virus in Human Exhaled Breath: An Observational Study. Fouchier RAM, editor. PLoS ONE. 2008;3(7):e2691. https://doi.org/10.1371/journal.pone.0002691

29. Lindsley WG, Blachere FM, Thewlis RE, Vishnu A, Davis KA, Cao G, et al. Measurements of Airborne Influenza Virus in Aerosol Particles from Human Coughs. Pekosz A, editor. PLoS ONE. 2010;5(11):e15100. https://doi.org/10.1371/journal.pone.0015100

30. Zhang H, Kang Z, Gong H, Xu D, Wang J, Li Z, et al. The digestive system is a potential route of 2019-nCov infection: a bioinformatics analysis based on singlecell transcriptomes [Internet]. Microbiology; 2020 Jan [acceso 2020 Mar 23]. Disponible en: http:// biorxiv.org/lookup/doi/10.1101/2020.01.30.927806 https://doi.org/10.1101/2020.01.30.927806

31. Xu H, Zhong L, Deng J, Peng J, Dan H, Zeng X, et al. High expression of ACE2 receptor of 2019-nCoV on the epithelial cells of oral mucosa. Int J Oral Sci. 2020;12(1):1-5. https://doi.org/10.1038/s41368-020-0074-x

32. Chai X, Hu L, Zhang Y, Han W, Lu Z, Ke A, et al. Specific ACE2 Expression in Cholangiocytes May Cause Liver Damage After 2019-nCoV Infection [Internet]. Genomics; 2020 Feb [acceso 2020 Mar 22]. Disponible en: http:// biorxiv.org/lookup/doi/10.1101/2020.02.03.931766 https://doi.org/10.1101/2020.02.03.931766

33. Diaz JH. Hypothesis: angiotensin-converting enzyme inhibitors and angiotensin receptor blockers may increase the risk of severe COVID-19. J Travel Med. 2020;taaa041. https://doi.org/10.1093/jtm/taaa041

34. HFSA/ACC/AHA Statement Addresses Concerns Re: Using RAAS Antagonists in COVID-19 [Internet]. American College of Cardiology. [acceso 2020 Mar 22]. Disponible en: https://www.acc.org/latest-in-cardiology/ articles/2020/03/17/08/59/hfsa-acc-aha-statementaddresses-concerns-re-using-raas-antagonists-in-covid-19

35. Simone C. Position Statement of the ESC Council on Hypertension on ACE-Inhibitors and Angi [Internet]. [acceso 2020 Mar 26]. Disponible en: https://www.escardio. org/Councils/Council-on-Hypertension-(CHT)/News/ position-statement-of-the-esc-council-on-hypertension-on- 
ace-inhibitors-and-ang, https://www.escardio.org/Councils/ Council-on-Hypertension-(CHT)/News/position-statementof-the-esc-council-on-hypertension-on-ace-inhibitors-and-ang

36. Muscarella LF. Recommendations for the prevention of transmission of SARS during GI endoscopy. Gastrointest Endosc. 2004;60(5):792-5. https://doi.org/10.1016/S0016-5107(04)01858-9

37. Chapman S. Hot air? BMJ. 2001;323(7327):1449-1449. https://doi.org/10.1136/bmj.323.7327.1449

38. World Health Organization. Rational use of personal protective equipment for coronavirus disease (COVID-19): interim guidance, 27 February 2020. 2020 [acceso 2020 Mar 22]; Disponible en: https://extranet.who.int/iris/restricted/handle/10665/331215

39. Johnston ER, Habib-Bein N, Dueker JM, Quiroz B, Corsaro E, Ambrogio M, et al. Risk of bacterial exposure to the endoscopist's faceduring endoscopy. GastrointestEndosc.2019;89(4):818-24. https://doi.org/10.1016/j.gie.2018.10.034

40. Repici A, Maselli R, Colombo M, Gabbiadini R, Spadaccini M, Anderloni A, et al. Coronavirus (COVID19) outbreak: what the department of endoscopy should know. Gastrointest Endosc. 2020;S0016510720302455. https://doi.org/10.1016/j.gie.2020.03.019

41. JOINT GI SOCIETY MESSAGE: COVID-19 Clinical Insights for Our Community of Gastroenterologists and Gastroenterology Care Providers [Internet]. Default. [acceso 2020 Mar 20]. Disponible en: https://www.asge. org/home/joint-gi-society-message-covid-19

42. Ayittey FK, Ayittey MK, Chiwero NB, Kamasah JS, Dzuvor C. Economic impacts of Wuhan 2019-nCoV on China and the world.J Med Virol. 2020;92(5):473-475. https://doi. org/10.1002/jmv.25706

43. World Health Organization. Disease commodity package - Novel Coronavirus (nCoV). Operational Support \& Logistics Disease Commodity Packages [Internet]. [acceso 2020 Mar 20]. Disponible en: https://www.who.int/emergencies/what-we-do/prevention-readiness/disease-commodity-packages/dcp-ncov.pdf

44. Shah SL, Carr-Locke D. ERCP for acute cholangitis: timing is everything. Gastrointestinal Endoscopy. 2020;91(4):761762. https://doi.org/10.1016/j.gie.2019.12.010

45. ESGE and ESGENA Position Statement on gastrointestinal endoscopy and the COVID-19 pandemic - European Society of Gastrointestinal Endoscopy (ESGE) [Internet]. [acceso 2020 Mar 22]. Disponible en: https://www.esge. com/esge-and-esgena-position-statement-on-gastrointestinal-endoscopy-and-the-covid-19-pandemic/

46. Sociedad Española de Endoscopia Digestiva (SEED). Recomendaciones de la SEED: Protección en Unidades de Endoscopia frente al COVID-19 [Internet]. [acceso 2020 Mar 23]. Disponible en: https://wseed.es/images/site/guia_clinica/2020/RecomendacionesSEED ProteccionUnidadesEndoscopia_Coronavirus.pdf

47. Johnston ER, Habib-Bein N, Dueker JM, et al. Risk of bacterial exposure to the endoscopists face during endoscopy.
Gastrointest Endosc. 2019; 89: 818-824. https://doi. org/10.1016/j.gie.2018.10.034

48. Cao Z, Zhang Q, Lu X, Pfeiffer D, Jia Z, Song H, Zeng DD. Estimating the effective reproduction number of the 2019-nCoV in China. [Internet]. [acceso 2020 Mar 23]. Disponible en: medRxiv 2020.01.27.20018952; doi: https: / doi.org/10.1101/2020.01.27.20018952

49. Zhang Y, Zhang X, Liu L, Wang H, Zhao Q. Suggestions of Infection Prevention and Control in Digestive Endoscopy During Current 2019-nCoV Pneumonia Outbreak in Wuhan, Hubei Province, China. [acceso 2020 Mar 23]; Disponible en: http://www.worldendo.org/wp-content/uploads/2020/02/ Suggestions-of-Infection-Prevention-and-Control-inDigestive-Endoscopy-During-Current-2019-nCoVPneumonia-Outbreak-in-Wuhan-Hubei-Province-China.pdf

50. Wang X, Pan Z, Cheng Z. Association between 2019$\mathrm{nCoV}$ transmission and $\mathrm{N} 95$ respirator use. J Hosp Infect [Internet]. 2020 Mar 3. Available from: http://www.ncbi. nlm.nih.gov/pubmed/3214288

51. Beilenhoff U, Biering H, Blum R, et al. Reprocessing of flexible endoscopes and endoscopic accessories used in gastrointestinal endoscopy: Position Statement of the European Society of Gastrointestinal Endoscopy (ESGE) and European Society of Gastroenterology Nurses and Associates (ESGENA) - Update 2018. Endoscopy. 2018;50:1205-1234.

52. Petersen BT, Cohen J, Hambrick RD, Buttar N, Greenwald DA, Buscaglia JM, et al. Multisociety guideline on reprocessing flexible GI endoscopes: 2016 update. Gastrointest Endosc. 2017;85(2):282-294.e1. https://doi.org/10.1016/j.gie.2016.10.002

53. Forbes N, Elmunzer BJ, Allain T, Chau M, Koury HF, Bass S, et al. Infection control in ERCP using a duodenoscope with a disposable cap (ICECAP): rationale for and design of a randomized controlled trial. BMC Gastroenterol. 2020;20(1):64. https://doi.org/10.1186/s12876-020-01200-7

54. Yang R, Ng S, Nichol M, Laine L. A cost and performance evaluation of disposable and reusable biopsy forceps in GI endoscopy. Gastrointest Endosc. 2000;51(3):266-70. https://doi.org/10.1016/S0016-5107(00)70353-1

55. Rutala WA, Weber D. Center for Disease Control and Prevention (CDC). Disinfection of Healthcare Equipment. Guideline for Disinfection and Sterilization in Healthcare Facilities (2008). Disponible en: https://www.cdc.gov/infectioncontrol/pdf/guidelines/disinfection-guidelines-H.pdf

56. Calderwood AH, Chapman FJ, Cohen J, Cohen LB, Collins J, Day LW, et al. Guidelines for safety in the gastrointestinal endoscopy unit. Gastrointest Endosc. 2014;79(3):363-72. https://doi.org/10.1016/j.gie.2013.12.015

57. CalderwoodAH,DayLW,MuthusamyVR,CollinsJ,Hambrick $\mathrm{RD}$, BrockAS, etal.ASGEguidelineforinfection controlduring GI endoscopy. Gastrointest Endosc. 2018;87(5):1167-79. https://doi.org/10.1016/j.gie.2017.12.009

58. Geller C, Varbanov M, Duval R. Human Coronaviruses: Insights into Environmental Resistance and Its 
Influence on the Development of New Antiseptic Strategies. Viruses. 2012; 4(11): 3044-68. https://doi.org/10.3390/v4113044

59. Rio C del, Malani PN. COVID-19-New Insights on a Rapidly Changing Epidemic. JAMA [Internet]. 2020 Feb 28 [acceso 2020 Mar 22]; Disponible en: https:// jamanetwork.com/journals/jama/fullarticle/2762510 https://doi.org/10.1001/jama.2020.3072

60. Soetikno R, Teoh A, Kaltenbach T, Lau J, Asokkumar R, Cabral-Prodigalidad P. Considerations in performing endoscopy during the COVID-19 pandemic; Joint GI Society Message: Gastroenterology COVID-19 Guide: Telehealth March 20, 2020.
61. Bai Y, Yao L, Wei T, Tian F, Jin D-Y, Chen L, et al. Presumed Asymptomatic Carrier Transmission of COVID-19. JAMA [Internet]. 2020 Feb 21 [acceso 2020 Mar 22]; Disponible en: https://jamanetwork.com/journals/jama/fullarticle/2762028 https://doi.org/10.1001/jama.2020.2565

62. Kampf G, Todt D, Pfaender S, Steinmann E. Persistence of coronaviruses on inanimate surfaces and their inactivation with biocidal agents. J Hosp Infect. 2020;104(3):246-51. https://doi.org/10.1016/j.jhin.2020.01.022

63. World Health Organization. Rational use of personal protective equipment for coronavirus disease 2019 (COVID19). Interim guidance 27 February 2020. 